\title{
Role of Endotoxemia in Cardiovascular Dysfunction and Mortality Escherichia coli and Staphylococcus aureus Challenges in a Canine Model of Human Septic Shock
}

\author{
Charles Natanson, Robert L. Danner, Ronald J. Elin, Jeanette M. Hosseini, Kevin W. Peart, Steven M. Banks, \\ Thomas J. MacVittie, Richard I. Walker, and Joseph E. Parrillo \\ Critical Care Medicine Department, Clinical Center, National Institutes of Health, Bethesda, Maryland 20892; \\ and Armed Forces Radiobiology Research Institute, Bethesda, Maryland 20814
}

\begin{abstract}
Using different types of bacteria and a canine model simulating human septic shock, we investigated the role of endotoxin in cardiovascular dysfunction and mortality. Either Escherichia coli (a microorganism with endotoxin) or Staphylococcus aureus (a microorganism without endotoxin) were placed in an intraperitoneal clot in doses of viable or formalin-killed bacteria. Cardiovascular function of conscious animals was studied using simultaneous radionuclide heart scans and thermodilution cardiac outputs. Serial plasma endotoxin levels were measured. $S$. aureus produced a pattern of reversible cardiovascular dysfunction over 7-10 d that was concordant $(P<0.01)$ with that of $E$. coli. Although this cardiovascular pattern was not altered by formalin killing ( $S$. aureus and $E$. coli), formalin-killed organisms produced a lower mortality and less myocardial depression $(P<0.01)$. S. aureus, compared to $E$. coli, produced higher postmortem concentrations of microorganisms and higher mortality $(P<0.025)$. $E$. coli produced significant endotoxemia $(P<0.01)$, though viable organisms (versus nonviable) resulted in higher endotoxin blood concentrations $(P<0.05)$. Significant endotoxemia did not occur with $S$. aureus. Thus, in the absence of endotoxemia, $S$. aureus induced the same cardiovascular abnormalities of septic shock as $E$. coli. These findings indicate that structurally and functionally distinct microorganisms, with or without endotoxin, can activate a common pathway resulting in similar cardiovascular injury and mortality.
\end{abstract}

\section{Introduction}

Septic shock is a highly lethal disorder that produces profound cardiovascular abnormalities in humans. Within 2-3 d of onset, patients typically have a decreased left ventricular ejection fraction with left ventricular dilation, and normal or increased cardiac output (1-3). In survivors of septic shock, these cardiovascular changes return to normal in $\sim 7-10 \mathrm{~d}$.

Gram negative bacteria and the endotoxin they produce, are closely associated with septic shock. Previous studies have shown that gram negative bacillary septicemia frequently produces shock and a high mortality. This shock state is thought

Presented in part at the National Meeting of the American Federation for Clinical Research in San Diego, CA, 1987.

Address reprint requests to Dr. Natanson, Critical Care Medicine Department, Clinical Center, Bldg. 10, Room 10-D-48, National Institutes of Health, Bethesda, MD 20892.

Received for publication 18 September 1987 and in revised form 15 July 1988.

The Journal of Clinical Investigation, Inc.

Volume 83, January 1989, 243-251 by many to be so distinctive that it constitutes a specific syndrome (4-6). However, recent clinical studies and experience indicate that many microorganisms, including fungi and gram positive bacteria (microorganisms without endotoxin), can produce a pattern of cardiovascular dysfunction similar to that of gram negative septic shock (1-3, 7-14).

Unlike septic shock caused by gram negative bacteria, septic shock caused by gram positive bacteria or fungi has not been shown to be closely linked to specific toxins or bacterial products. Peptidoglycan, a structural component of the cell wall of gram positive bacteria, can produce endotoxin-like effects; however, the biological activity of endotoxin is quantitatively greater $\left(5 \times 10^{9}\right)$ than that of peptidoglycan $(15)$. The cardiovascular effects of these peptidoglycans have not been previously evaluated. Although controversial, some studies suggest that microorganisms without endotoxin may cause septic shock by disrupting the mucosal barrier of the host intestines so that gram negative bacteria (or their endotoxin) leak into the bloodstream. Proponents of this theory suggest that this route is the final common pathway of irreversible shock produced from any etiology (16-18).

In the present study, the cardiovascular changes produced by a gram negative bacteria (Escherichia coli) and a gram positive bacteria (Staphylococcus aureus) were compared in a canine model that was designed to simulate closely human septic shock $(19,20)$. We examined the relationship of cardiovascular changes to microorganism viability for both types of bacteria. Plasma endotoxin was serially determined during the course of infection using a sensitive chromogenic limulus amebocyte lysate assay to study the potential role of endotoxin in producing the severe hemodynamic abnormalities found in septic shock.

\section{Methods}

Experimental design. The general protocol used in this study has been previously described (19). The specific protocol used in this study is diagramed in Fig. 1. A complete hemodynamic evaluation and routine laboratory blood analysis were performed on each dog at the baseline time point, which was 1 wk before surgery. At each time point, we inserted intravascular catheters using local subcutaneous anesthesia (1\% lidocaine) and obtained blood samples for laboratory analysis. Hemodynamic data were then obtained in awake nonsedated dogs simultaneously from intravascular pulmonary and femoral artery catheters and from gated radionuclide cineangiography of the left ventricle. After giving animals an intravascular volume infusion, we then repeated simultaneous hemodynamic and radionuclide studies. Intravascular catheters were removed after completing the evaluation.

Surgery was performed as previously described (19). On day 0 , we placed a fibrin clot containing 1 microbiological preparation in the peritoneal cavity (Table I). 86 2-yr-old beagles, weighing a mean \pm SEM of $11.47 \pm 0.21 \mathrm{~kg}$, were used in this experiment. Comprehensive hemo- 


\section{CANINE MODEL OF SEPTIC SHOCK}

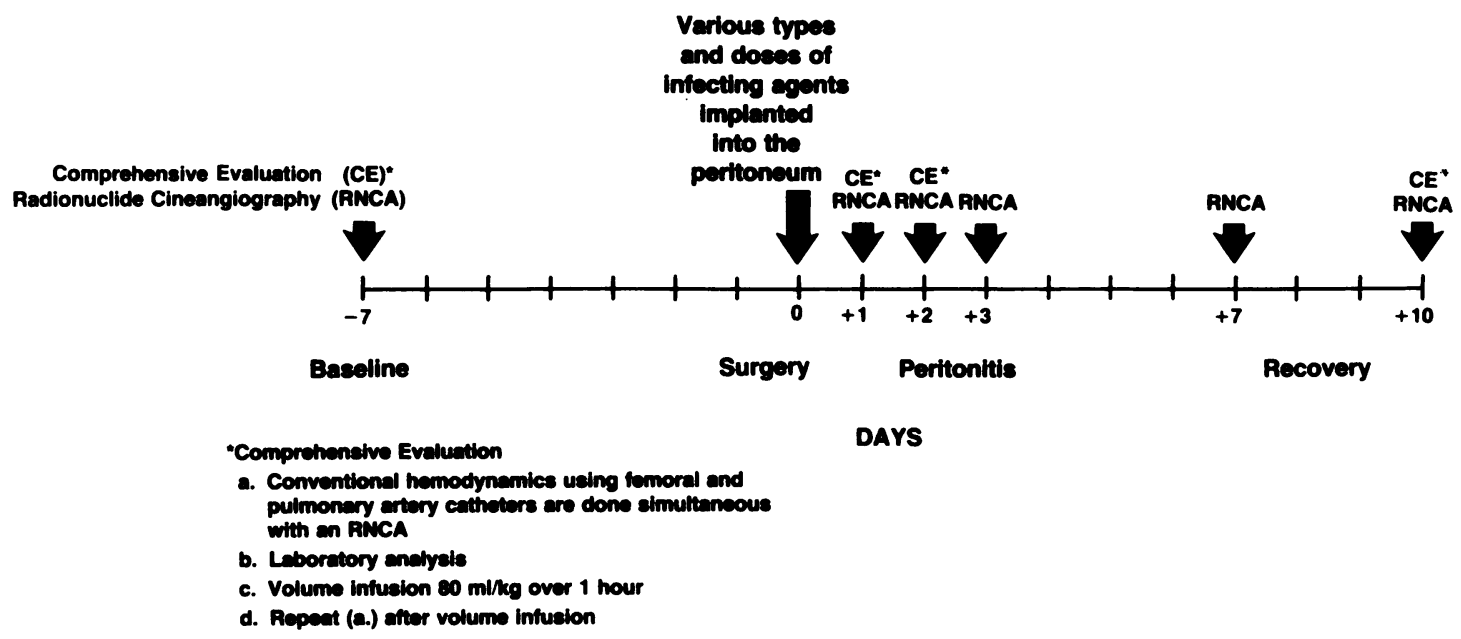

Figure 1. This figure outlines the design and time course of the experiment. All dogs in the study had a clot implanted in the peritoneal cavity. The clot was either sterile (controls) or infected with various doses of viable or formalin-killed bacteria (E. coli or $S$. aureus).

dynamic and laboratory evaluations, as described for the baseline time point, were repeated on days 1,2 , and 10 postsurgery.

Animals receiving viable $E$. coli $\left(30 \times 10^{9}\right.$ organisms per $\mathrm{kg} / \mathrm{body}$ wt) and 6 of 14 control dogs (reported previously) were evaluated at all time points except day $1(19,20)$. Comparisons of results were only made between animals receiving similar treatments at the same time points.

Preparation of clots containing viable and formalin-killed bacteria. The strains of $E$. coli and $S$. aureus used in the experiments were obtained from patients with sepsis. The $S$. aureus was identified as a nontoxic shock type pathogen (TSST-1) by the Centers for Disease Control (Atlanta, GA). The $S$. aureus was further identified as a virulent capsular serotype $8(21)$. The $E$. coli strain was characterized as a nonhemolytic, nonencapsulated, serum sensitive (human and dog), colicin v negative, serotype $086 ; \mathrm{H} 8(22,23)$. All experiments throughout this paper were performed with these two strains of bacteria unless otherwise stated.

Bacteria were stored in 1-ml aliquots of bacto-peptone infusion broth (Difco Laboratories, Detroit, $\mathrm{MI}$ ) and glycerol at $-70^{\circ} \mathrm{C}$. To prepare viable bacterial doses, we inoculated $500 \mathrm{ml}$ of brain-heart infusion broth with a $1-\mathrm{ml}$ aliquot of thawed bacteria. Bacteria were incubated for $18 \mathrm{~h}$, centrifuged, and then washed twice in sterile saline. Concentration of bacteria in the final suspension (number of colony forming units) was measured by turbidimetry. This method was used to compare the turbidity of newly grown bacterial suspensions to that of known standards. The concentration of bacteria was then quantified by plating successive 10 -fold dilutions of the bacterial suspension onto sheep blood agar and by scoring visible colonies after a 24-h incubation at $37^{\circ} \mathrm{C}$.

Nonviable bacterial doses were prepared using the same method as that of viable bacteria, except that during the final suspension of saline, bacteria were centrifuged again and were reconstituted with $5 \mathrm{~cm}^{3}$ of $4 \%$ formalin for $30 \mathrm{~min}$. Bacteria were then resuspended with sterile saline to reconstitute the original concentration of bacteria. The quantity of bacteria in the final suspension was then reconfirmed by turbidimetry. A second viability study was performed on sheep blood agar to confirm $100 \%$ bacterial death of all nonviable bacteria. The doses of formalin-killed and viable bacteria, as determined by turbidimetric and viability studies, are shown in Table I. Bacteria were added to the fibrin clot using the method previously described (19).

Physiologic measurements and hemodynamic calculations. All hemodynamic measurements were made using techniques previously described (19). Measurements were obtained from indwelling femoral and balloon flotation pulmonary artery catheters in nonanesthetized animals resting quietly in slings. Radionuclidegated blood pool scanning was performed using conventional techniques to determine the left ventricular ejection fraction in awake nonsedated animals (19).

The hemodynamic data were indexed by animal body weight in kilograms. The following values were calculated according to the standard formulas previously described: cardiac index $(\mathrm{CI})^{1}(\mathrm{ml} / \mathrm{kg}$ per $\mathrm{min}$ ), and stroke volume index (SVI) (ml/kg per beat) (19). The end diastolic volume index (EDVI) $(\mathrm{ml} / \mathrm{kg}$ ) and end systolic volume index (ESVI) $(\mathrm{ml} / \mathrm{kg})$ were calculated from hemodynamic studies and radionuclide scans using the formulas EDVI = SVI (from thermodilution cardiac output)/EF (from radionuclide cineangiography) and ESVI $=$ EDVI - SVI.

Limulus amebocyte lysate assay. Serial blood samples were obtained from all dogs at baseline, days 1,2 , and 10 postsurgery. Samples $(3 \mathrm{ml})$ were placed in sterile, pyrogen-free, sodium heparinized glass tubes ( 2 U. S. Pharmacopeia units $/ \mathrm{ml}$ of whole blood). Additional blood specimens were obtained from dogs infected with $S$. aureus at 4 and $10 \mathrm{~h}$ postsurgery and from nonsurviving dogs immediately after death to test for endotoxemia. The blood was continuously mixed until centrifuged at $400 \mathrm{~g}$ for $10 \mathrm{~min}$; the plasma was transferred into pyrogen-free screw-capped glass tubes and stored at $-20^{\circ} \mathrm{C}$ until assayed. No difference was observed between endotoxin levels of platelet-rich or platelet-poor plasma specimens $(n=18, P>0.5)$. Endotoxin concentrations were determined using a quantitative chromogenic limulus amebocyte lysate assay (Whittaker M.A. Bioproducts, Walkersville, MD), which is sensitive to $10 \mathrm{pg} / \mathrm{ml}$ of U.S. standard endotoxin. Specimens were first diluted 1 to 5 and heated to $100^{\circ} \mathrm{C}$ for $10 \mathrm{~min}$ to remove nonspecific inhibition $(24,25)$. The sample $(50 \mu \mathrm{l})$ and limulus amebocyte lysate $(50 \mu \mathrm{l})$ were then combined and incubated for $10 \mathrm{~min}$ at $37^{\circ} \mathrm{C}$. The chromogenic substrate $(100 \mu \mathrm{l})$ was then added. After 3 min, the reaction was stopped by adding $50 \%$ acetic acid $(100 \mu \mathrm{l})$. In samples with endotoxin, free $p$-nitroaniline is released from the chromogenic substrate producing a color change that can be measured by spectrophotometry at $\mathbf{4 0 5} \mathrm{nm}$. Endotoxin concentrations in endotoxin

1. Abbreviations used in this paper: CI, cardiac index; EDVI, end diastolic volume index; EF, ejection fraction; ESVI, end systolic volume index; LV, left ventricle; MAP, mean arterial pressure; PCWP, pulmonary capillary wedge pressure. 


\begin{tabular}{|c|c|c|c|c|c|c|c|}
\hline \multirow[b]{3}{*}{ No. of bacteria $\times 10^{9} / \mathrm{kg}$ body wt ( \pm SEM) } & \multicolumn{7}{|c|}{ Bacteria } \\
\hline & \multirow[b]{2}{*}{$\begin{array}{cc}* & 1 \\
\ddagger & 1.0 \\
( \pm 0.1)\end{array}$} & \multicolumn{2}{|c|}{ S. aureus } & \multicolumn{4}{|c|}{ E. coli } \\
\hline & & $\begin{array}{c}7 \\
11.1 \\
( \pm 0.1)\end{array}$ & $\begin{array}{l}30 \\
28.6 \\
( \pm 2.7)\end{array}$ & $\begin{array}{c}7 \\
7.4 \\
( \pm 1.1)\end{array}$ & $\begin{array}{c}14 \\
15.5 \\
( \pm 0.3)\end{array}$ & $\begin{array}{c}30 \\
28.5 \\
( \pm 1.0)\end{array}$ & $\begin{array}{l}30 \\
21.6 \\
( \pm 1.3)\end{array}$ \\
\hline $\begin{array}{l}\text { Viable (V) or formalin-killed (FK) bacteria } \\
\text { FK }\end{array}$ & & $\mathbf{v}$ & $\mathbf{v}$ & FK & $\mathbf{V}$ & $\mathbf{V}$ & $\mathbf{v}$ \\
\hline No. of dogs & & 8 & 4 & 13 & 8 & 10 & 21 \\
\hline No. of deaths & & $\mathbf{0}$ & 4 & 0 & 0 & 0 & 13 \\
\hline $\begin{array}{ll}\text { Percent mortality } & \\
& 0\end{array}$ & & 0 & 100 & 0 & 0 & $\mathbf{0}$ & 62 \\
\hline
\end{tabular}

* Turbidimetric determination. ${ }^{\ddagger}$ Viable count (mean \pm SE). Data from these groups previously reported $(18,19)$.

units per $\mathrm{ml}(1 \mathrm{EU} / \mathrm{ml}=0.1 \mathrm{mg}$ each of $\mathrm{U}$. S. standard endotoxin) were determined from a standard curve based on known amounts of purified endotoxin assayed in $\mathrm{H}_{2} \mathrm{O}$.

The reactions were carried out on plastic microtiter tissue culture plates (Costar, Cambridge, MA) and measured with a microtiter plate reader (Titertek, Multiskan MC; Flow Laboratories, McLean, VA).

Quantitative blood and tissue cultures. Quantitative blood and tissue cultures were done for each group of dogs to compare generation times and intrinsic invasive properties of these viable strains of $S$. aureus and $E$. coli. Six 2 -yr-old beagles (mean $\pm \mathrm{SE}$ weight $12.5 \pm 0.8 \mathrm{~kg}$ ) had a clot with $7 \times 10^{9}$ per kg body wt organisms implanted intraperitoneally. Three dogs received $E$. coli and three dogs received $S$. aureus. Quantitative blood cultures were obtained from dogs before surgery, 2 $\mathrm{h}$ after surgery, and then every $8 \mathrm{~h}$ for $24 \mathrm{~h}$. From previous experiments, we knew that $S$. aureus was more rapidly lethal than $E$. coli. To obtain liver, lung, and spleen tissue for quantitative tissue cultures and to perform quantitative organ cultures at the same time for dogs receiving $S$. aureus and dogs receiving $E$. coli, we decided to kill a dog receiving $E$. coli whenever a $\operatorname{dog}$ receiving $S$. aureus died. Consequently, we then had tissue cultures obtained at comparable time points for dogs challenged with $S$. aureus and dogs challenged with $E$. coli. All dogs surviving $24 \mathrm{~h}$ were killed with T-61 Euthanasia Solution (Taylor Pharmacal Co., Decatur, IL).

Quantitative blood culture concentrations were measured in petri dishes by plating successive 10-fold dilutions of $1 \mathrm{ml}$ of blood in pour tubes and then scoring by counting visible colonies after $24 \mathrm{~h}$ incubation at $37^{\circ} \mathrm{C}$. The quantitative tissue culture concentrations were obtained by homogenizing $1 \mathrm{~g}$ of tissue with $3 \mathrm{ml}$ of tryptic soy broth and then doing successive dilutions with pour tubes as above.

Experiments with another $E$. coli strain. Since $E$. coli strain 086; $\mathrm{H8}$ is not a common human pathogen, and is not encapsulated, hemolytic, and serum resistant, virulence factors commonly associated with human infections $(22,23)$, we repeated a number of experiments with $E$. coli strain $06 ; \mathrm{H} 1 ; \mathrm{K} 2$. This $E$. coli, which is frequently found in extraintestinal human disease, was provided by the Statens Serum Institut (Copenhagen, Denmark). This organism is encapsulated, hemolytic, and serum-resistant $(22,23)$.

In these additional experiments, 14 purebred beagles (10-12 kg) were used. 11 animals had a clot infected with the $E$. coli serotype $06 ; \mathrm{H} 1 ; \mathrm{K} 2$ implanted intraperitoneally, and for comparison purposes, 3 dogs had a clot infected with the original $S$. aureus (capsular serotype $8)$ implanted intraperitoneally. Four dogs had viable $E$. coli $\left(1 \times 10^{9} \mathbf{~ k g}\right.$ body $w t)$ implanted for serial hemodynamic evaluations at baseline, days 1,2 , and recovery. Three animals had viable $E$. coli $\left(7 \times 10^{9} \mathrm{~kg}\right.$ body wt) and three animals had viable $S$. aureus $\left(7 \times 10^{9} \mathrm{~kg}\right.$ body wt) implanted for comparison of quantitative tissue and blood culture examinations. Four dogs also had viable $E$. coli $\left(7 \times 10^{9} \mathrm{~kg}\right.$ body $\left.\mathrm{wt}\right)$ implanted for survival studies only. These additional studies are described in detail below in Results.

Statistical methods. The mean values were compared with the use of the appropriate $t$ test. The time courses of a hemodynamic variable (e.g., EF) were summarized at each of four time points (baseline, days 1,2 , and 10 postsurgery) by assigning ranks to the corresponding mean values of the variable in question (Figs. 2 and 3). Patterns of hemodynamic responses to various treatments were assessed with the use of the Kendall coefficient of concordance among the six groups of dogs (26). A coefficient of concordance value of 1 indicates complete agreement among the assigned ranks, and a value of 0 indicates maximal disagreement. The shaded areas in Figs. 2 and 3 represent the normal ranges based on data from 100 control dogs, the width of the range being adjusted to the size of the experimental group.

Relative frequencies of death were compared using the Fisher exact test. The doses of viable and nonviable $S$. aureus, for which relative frequency of death was compared, were not equal. Nevertheless, the highest dose of viable organism administered $\left(7 \times 10^{9}\right)$ was associated with $100 \%$ lethality. This dose was less than one-fourth the dose of nonviable organisms $\left(30 \times 10^{9}\right)$, which caused no deaths.

Endotoxin levels were adjusted to baseline time points (Table III) (27). Median endotoxin levels on days 1 and 2 were compared using a Mann-Whitney test (26); significance was adjusted by a modified Bonferonni procedure (28).

Blood cultures were taken at baseline, $2 \mathrm{~h}$, and then every $8 \mathrm{~h}$ for 24 h; organ tissue cultures were also taken immediately after death from dogs infected with $S$. aureus and immediately after sacrifice from dogs infected with $E$. coli. Bacterial colony counts were logged. Log counts from blood cultures were subjected to a three-way analysis of variance (dogs nested within type of bacterial infection $\times$ time) whereas log counts from each set of organ cultures were treated by a one-way analysis in which comparisons were made of data from corresponding organs with different types of infection. Quantitative culture results from the two strains of $E$. coli and the strain of $S$. aureus were assessed using a Bartholomew test to compare differences among ordered means (29) (S. aureus $>E$. coli $06 ; \mathrm{H} 1 ; \mathrm{K} 2>E$. coli $086 ; \mathrm{H} 8)$. For each microorganism, results from the three organs cultured (liver, lung, and spleen) were found to be pairwise independent. Accordingly, the levels of significance of the Bartholomew test were combined in a Fisher Omnibus test:

\section{Results}

Blood cultures and clinical manifestations. $2 \mathrm{~d}$ postsurgery, all surviving dogs infected with viable bacteria had species-spe- 

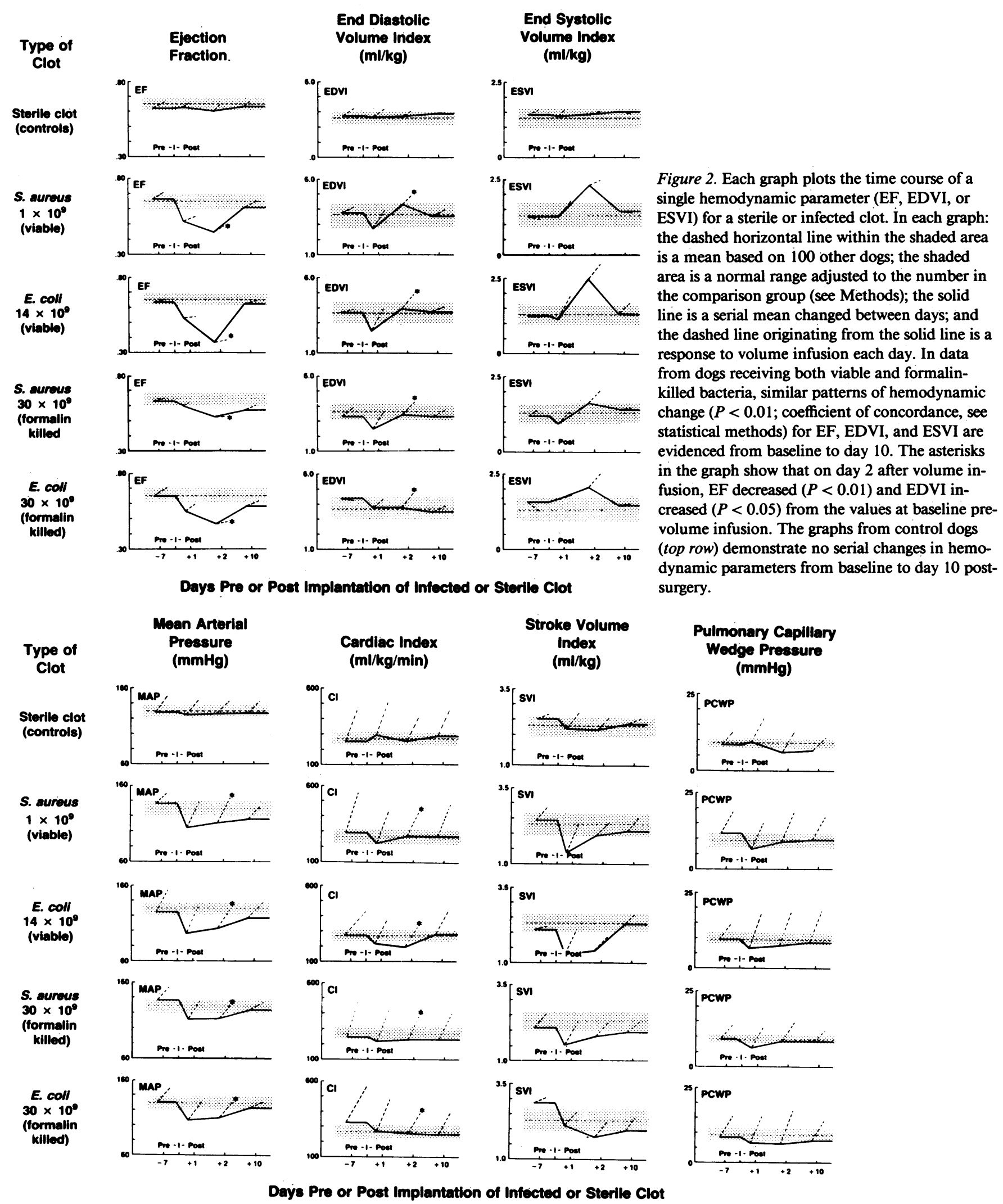

Figure 3. The format is the same as Fig. 2, except that the time course is plotted for four different hemodynamic parameters (MAP, CI, SVI, PCWP). In data from dogs receiving both viable and formalin-killed bacteria, similar patterns $(P<0.01$, coefficient of concordance) of change in MAP, CI, SVI, and PCWP are evident from baseline to day 10. The asterisks in the graph show that on day 2 after volume infusion, when the MAP returned to normal, the $\mathrm{CI}$ in- creased $(P<0.01)$ from the value at baseline prevolume infusion. Thus, Figs. 2 and 3 demonstrate that on day 2, after fluids returned MAP to normal, LVEF decreased, EDVI increased, and CI increased (a "hyperdynamic" response typical of human septic shock). Control animals (top row) demonstrated no serial changes in any hemodynamic parameters. 
cific positive blood cultures for the implanted microorganisms. All dogs implanted with formalin-killed bacteria had sterile blood cultures on days 1 and 2 postsurgery. All dogs had sterile blood cultures at baseline and at recovery. On days 1 and 2 postsurgery, all dogs implanted with bacteria were febrile, weak, and lethargic, showing signs of septic shock. Animals receiving viable bacteria appeared sicker (more lethargic and prostrate) than those receiving nonviable bacteria. As previously reported, control dogs receiving sterile clots had sterile blood cultures, and were afebrile and healthy throughout the study $(19,20)$. Despite lack of antibiotic treatment or pressor therapy, all 14 control dogs and 55 of the 74 infected dogs recovered completely within 7-10 d of surgery (Table I). 13 of 21 dogs died in the group receiving the highest dose of viable $E$. coli $\left(30 \times 10^{9}\right)(20)$; all 4 dogs died in the group receiving the moderate dose of viable $S$. aureus $\left(7 \times 10^{9}\right)$ (Table I).

Comparison of serial hemodynamics with different types of bacteria. During the experiment, serial mean changes in hemodynamic parameters were observed in some dogs implanted with infected and sterile clots (Figs. 2 and 3). Figs. 2 and 3 display multiple graphs: each plot shows the time course of a specific cardiovascular parameter during a 10-d period (baseline, days 1,2 , and 10 postsurgery). To simplify illustration, we show only some of the groups of dogs from the viable and formalin-killed groups of $S$. aureus and $E$. coli in Figs. 2 and 3; however, all groups of dogs showed the same hemodynamic pattern. The overall statistical comparison of hemodynamic changes is based on data from all groups (Table I).

To determine if qualitative changes in hemodynamic parameters were similar for different bacteria, we calculated the coefficient of concordance (see Methods). The coefficient of concordance determines if graded hemodynamic responses occurred at similar time points in different groups.

When comparing the pattern of hemodynamic changes among all groups of dogs receiving various doses of viable and formalin-killed $E$. coli and $S$. aureus, we noted a strong concordance for the serial changes in hemodynamics (see Methods): $\mathrm{EF}=0.94,(P<0.001)$; EDVI $=0.50,(P<0.05)$; $\mathrm{ESVI}=0.68,(P<0.01)$; MAP $=0.83,(P<0.01)$; $\mathrm{CI}=0.61$, $(P<0.01)$; SVI $=0.74,(P<0.01)$; and PCWP $=0.61,(P$ $<0.01)$. As previously described, control dogs had no significant changes in hemodynamic parameters when parameters were compared to those at baseline (see top panel, Figs. 2 and 3) $(19,20)$.

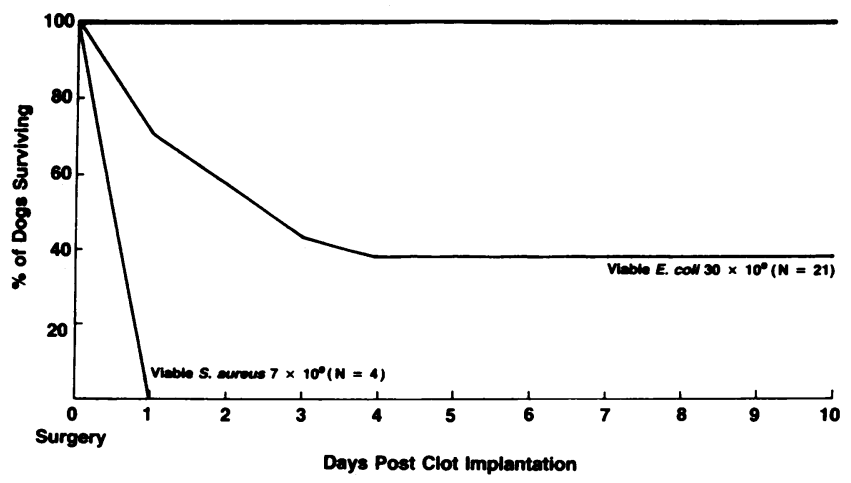

Figure 4. This figure, which plots data from dogs infected with 30 $\times 10^{9}$ viable $E$. coli and $7 \times 10^{9}$ viable $S$. aureus, compares the percentage of dogs surviving vs. the days postsurgery.

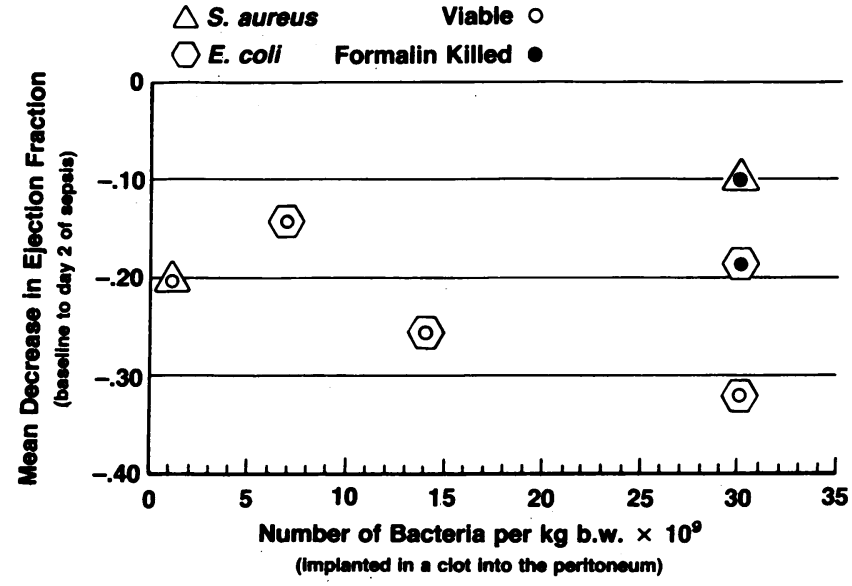

Figure 5. The data in this graph is from dogs infected with viable or formalin-killed $S$. aureus (serotype 8) or $E$. coli (serotype 086; H8). The figure compares the number of bacteria implanted vs. the mean decrease in LVEF between baseline and day 2 of sepsis. Please see text for a full discussion of these experimental groups. Please note: Not pictured in this graph are results of an additional four dogs infected with another $E$. coli strain (serotype $06 ; \mathrm{H1} ; \mathrm{K} 2$ ) containing more virulence factors associated with human infection (see Methods). Challenges with this more virulent $E$. coli $\left(1 \times 10^{9}\right.$ colony forming units per $\mathrm{kg}$ body wt) caused a mean decrease in LVEF from baseline to day 2 of -0.16 .

Effect of volume infusion on serial hemodynamics with different bacteria. On day 2 of sepsis after volume infusion (noted by asterisks in Figs. 2 and 3; the volume necessary to bring the MAP back to normal), all groups of infected dogs, when compared to baseline, manifested a decreased LVEF $(P<0.001)$, increased EDVI $(P<0.05)$, and increased CI $(P<0.01)$ (hyperdynamic response). Both viable and formalin-killed $E$. coli or $S$. aureus produced similar patterns of change in cardiovascular function.

Survival with different species of bacteria. Fig. 4 plots the percentage of survivors in each group vs. the number of days postsurgery. No dogs died in the groups receiving sterile clots (no bacteria), viable $E$. coli $\left(7 \times 10^{9} ; 14 \times 10^{9}\right)$, viable $S$. aureus $\left(1 \times 10^{9}\right)$, formalin-killed $E$. coli $\left(30 \times 10^{9}\right)$, or formalin-killed $S$. aureus $\left(30 \times 10^{9}\right)$. Of the dogs infected with the highest number of colony forming units of viable $E$. coli $\left(30 \times 10^{9}\right)$, there was a $62 \%$ mortality. Dogs receiving only a moderate dose of $S$. aureus $\left(7 \times 10^{9}\right)$ had a $100 \%$ mortality. Thus, when comparing the number of bacteria (per colony forming unit implanted intraperitoneally), we observed that $S$. aureus caused higher mortality than $E$. coli $(P<0.01)$. Furthermore, when comparing the number of viable to nonviable bacteria (either $S$. aureus or $E$. coli), we found viable bacteria to be more lethal $(P<0.01)$.

Comparison of decrease in cardiac function of different types of bacteria. Fig. 5 plots the mean decrease in LVEF between baseline and day 2 of sepsis vs. the number of bacteria (colony forming units) implanted in the fibrin clot. As the number of viable $E$. coli increased, the LVEF decreased ( $P$ $<0.01)(20)$. The LVEF decreased $(P<0.01)$ more with viable $S$. aureus $\left(1 \times 10^{9}\right)$ or with viable $E$. coli $\left(30 \times 10^{9}\right)$ (per colony forming unit implanted intraperitoneally), than with formalin-killed bacteria $\left(30 \times 10^{9}\right)$. Viable $S$. aureus $\left(1 \times 10^{9}\right)$ produced greater $(P<0.01)$ myocardial depression than viable $E$. coli $\left(7 \times 10^{9}\right)$. $S$. aureus was more dependent $(P<0.01)$ on 
microorganism viability than $E$. coli was to produce myocardial depression. To demonstrate this last point, we made several comparisons in Table II. A low dose of viable $S$. aureus (1 $\times 10^{9}$ ) decreased LVEF more than a high dose of formalinkilled $S$. aureus $\left(30 \times 10^{9}\right)$; however, a low dose of viable $E$. coli $\left(7 \times 10^{9}\right)$ decreased LVEF less than a high dose of formalin-killed $E$. coli $\left(30 \times 10^{9}\right)$. These contrasting LVEF results from low doses of viable and high doses of nonviable organisms were significantly different $(P<0.01)$.

Endotoxin levels. Median endotoxin values measured at 24 $h$ and $48 \mathrm{~h}$ were combined and adjusted to baseline for dogs receiving sterile clots, viable $E$. coli $\left(14 \times 10^{9}\right)$, nonviable $E$. coli $\left(30 \times 10^{9}\right)$, and viable $S$. aureus $\left(1 \times 10^{9}\right)$. Dogs receiving sterile clots or $S$. aureus clots had no significant endotoxemia compared to baseline determinations. Dogs receiving viable and nonviable $E$. coli when compared to dogs receiving $S$. aureus or sterile clots had significant endotoxemia $(P<0.01$; Table III). Dogs receiving viable $E$. coli when compared to dogs receiving nonviable $E$. coli had greater endotoxemia ( $P$ $<0.05$ ). By day 10 , endotoxin levels of dogs from all four groups were not significantly different from endotoxin levels at baseline. Dogs receiving viable $S$. aureus $\left(1 \times 10^{9}\right)$ had additional endotoxin levels measured at 4 and $10 \mathrm{~h}$ postsurgery and had no significant endotoxemia. Furthermore, dogs in the group receiving lethal doses of $S$. aureus $\left(7 \times 10^{9}\right)$ had endotoxin levels measured at 4 and $10 \mathrm{~h}$ postsurgery, and immediately postmortem, and had no significant endotoxemia.

Quantitative blood and tissue cultures. Dogs infected with $S$. aureus to obtain quantitative cultures died of septic shock at a mean $( \pm S E)$ of $15.6 \pm 0.7 \mathrm{~h}$ post-clot implantation. Since the $E$. coli dose of $7 \times 10^{9}$ per $\mathrm{kg}$ body wt was nonlethal within 24 $h$ after clot implantation, the dogs given this dose were each sacrificed at the time of death of one of the dogs treated with $S$. aureus. Quantitative blood cultures were not significantly different between the dogs infected with this $S$. aureus and $E$. coli at 0,2 , and $8 \mathrm{~h}$ post-clot implantation (Table IV). However, comparison of tissues revealed that postmortem liver, lung, and spleen concentrations of bacteria were greater $(P<0.025)$ in dogs infected with $\dot{S}$. aureus than in dogs infected with $E$. coli.

Experiment with another $E$. coli strain. To address the question regarding the behavior of an $E$. coli organism with more virulence characteristics in this animal model, we performed further studies on 11 dogs who were infected with an $E$. coli that manifested more virulence factors associated with human infection $(22,23)$. An additional four dogs were in-

Table II. Decrease (Mean \pm SE) in Ejection Fraction (Percent) from Baseline to Day 2 According to Type and Viability of Organism

\begin{tabular}{lccc}
\hline & Low dose* viable & High dose nonviable & Difference \\
\hline S. aureus & $-20.8 \pm 3.5(n=8)$ & $-10.3 \pm 1.5(n=13)$ & -10.5 \\
E. coli & $-14.3 \pm 2.6(n=8)$ & $-18.8 \pm 3.5(n=8)$ & $\frac{+4.5}{15.0 \pm 5.4^{\ddagger}}$
\end{tabular}

\footnotetext{
* Low dose viable for $E$. coli was $7 \times 10^{9} \mathrm{CFU} / \mathrm{kg}$ body wt and for $S$. aureus was $1 \times 10^{9} \mathrm{CFU} / \mathrm{kg}$ body wt. The lower dose for $S$. aureus was chosen to be $1 \times 10^{9} \mathrm{CFU} / \mathrm{kg}$ body wt because the $7 \times 10^{9}$ CFU/kg body wt dose produced $100 \%$ mortality. ${ }^{\ddagger} P<0.01$.
}

Table III. Median Values (and Range) for Endotoxemia during Septic Shock

\begin{tabular}{|c|c|c|c|c|}
\hline & $\begin{array}{l}\text { Sterile clots } \\
\text { Controls }\end{array}$ & $\begin{array}{l}\text { S. aureus } \\
\text { Viable }\end{array}$ & $\begin{array}{l}\text { E. coli } \\
\text { Viable }\end{array}$ & $\begin{array}{c}\text { E. coli } \\
\text { Formalin-killed }\end{array}$ \\
\hline & & $\begin{array}{l}1 \times 10^{\circ} \\
C F U / \mathrm{kg} \\
\text { body wt }\end{array}$ & $\begin{array}{l}14 \times 10^{\circ} \\
C F U / \mathrm{kg} \\
\text { body wt }\end{array}$ & $\begin{array}{l}30 \times 10^{\circ} \\
C F U / \mathrm{kg} \\
\text { body wt }\end{array}$ \\
\hline \multicolumn{5}{|c|}{$\begin{array}{l}\text { Endotoxin } \\
\text { concentration } \\
(\mathrm{EU} / \mathrm{ml})^{*}\end{array}$} \\
\hline $\begin{array}{l}\text { Median } \\
\text { Range }\end{array}$ & $\begin{array}{c}0.8 \\
(0-17)\end{array}$ & $\begin{array}{c}0.0 \\
(0-64)\end{array}$ & $\begin{array}{c}45.5 \\
(3.72-74.8)\end{array}$ & $\begin{array}{c}2.4 \\
(05-774)\end{array}$ \\
\hline
\end{tabular}

* One endotoxin unit (EU) $=$ the activity of $100 \mathrm{pg}$ of U.S. Standard Endotoxin.

fected with another $E$. coli strain serotype $06 ; \mathrm{H} 1 ; \mathrm{K} 2$ at a dose of $1 \times 10^{9}$ viable colony forming units per kg body wt. Hemodynamic testing of these dogs was the same as that used for all the dogs described earlier (see Results). Hemodynamic data collected on each of $4 \mathrm{~d}$ (baseline, days $1,2,10$ postsurgery) were reduced to ranks that were compared to the corresponding mean ranks representing averages of hemodynamic data over the original six groups of dogs (see Methods). Such comparisons were made for the following hemodynamic variables: PCWP, MAP, CI, SVI, EF, EDVI, and ESVI. No significant difference was found in the respective paired sets of ranks (levels of significance ranged from 0.08 to 0.99 with an overall level of 0.54 ). Therefore, we concluded that the findings obtained with this strain of $E$ : coli tended to be concordant with the results observed earlier. Six additional dogs were studied, using the quantitative blood and tissue culture methods previously described (see Results). Three dogs were infected with $E$. coli (serotype strain $06 ; \mathrm{H} 1 ; \mathrm{K} 2$ ) and, for comparison, three dogs were infected with the $S$. aureus (capsular serotype 8 ). Both microorganisms were implanted in the dogs peritoneum at a dose of $7 \times 10^{9}$ viable colony forming units per kg body wt. Results from quantitative blood cultures were not significantly different between this strain of $E$. coli and $S$. aureus at 0,2 , and $8 \mathrm{~h}$ post-clot implantation (Table IV). However, $S$. aureus (capsular serotype 8) per colony forming unit implanted intraperitoneally, produced greater concentrations of bacteria $(P$ $<0.025$ ) in postmortem tissue (liver, lung, and spleen) than that of $E$. coli serotype $06 ; \mathrm{H} 1 ; \mathrm{K} 2$ and, as described previously, that of $E$, coli serotype $086 ; \mathrm{H} 8$.

Finally, an additional four dogs were infected with the virulent strain $E$. coli serotype $06 ; \mathrm{H} 1 ; \mathrm{K} 2$ at a dose of $7 \times 10^{9}$ viable colony forming units per $\mathrm{kg}$ body wt for survival studies alone using the same procedure as that described previously (see Results). Of these 4 dogs infected with $E$. coli (serotype $06 ; \mathrm{H} 1 ; \mathrm{K} 2$ ), one animal died on day 8 post-clot implantation and the remaining 3 dogs survived. As described earlier, the $S$. aureus (capsular serotype 8$)$ at this dose $\left(7 \times 10^{9}\right.$ viable bacteria per $\mathrm{kg}$ body wt implanted intraperitoneally) was $100 \%$ lethal within $24 \mathrm{~h}$. Thus, $S$. aureus (capsular serotype 8) compared to $E$. coli (serotype $06 ; \mathrm{H} 1 ; \mathrm{K} 2$ ), per colony forming unit implanted intraperitoneally was more rapidly lethal $(P$ $<0.02$ ), and, as stated earlier, this $S$. aureus was also more lethal than $E$. coli serotype $086 ; \mathrm{H8}$. Thus, compared to two $E$. coli strains $(06 ; \mathrm{H} 1 ; \mathrm{K} 2$ and $086 ; \mathrm{H} 8), S$. aureus (capsular sero- 
Table IV. Quantitative Blood and Tissue Cultures in a Canine Model of Septic Shock Employing a Peritoneal Implant of Infected Clots

\begin{tabular}{|c|c|c|c|c|c|c|c|c|}
\hline \multirow{3}{*}{$\begin{array}{l}\text { Type of viable } \\
\text { bacteria }\end{array}$} & \multirow{3}{*}{$\begin{array}{l}\begin{array}{l}\text { No. of CFU in } \\
\text { peritoneal clot }\end{array} \\
\text { per } k g \text { body wt }\end{array}$} & \multirow{3}{*}{$\begin{array}{l}\text { No. of } \\
\text { dogs* }\end{array}$} & & & & \multicolumn{3}{|c|}{$\begin{array}{l}\text { No. of CFU per gram of postmortem tissue } \\
\text { (geometric mean) }\end{array}$} \\
\hline & & & \multicolumn{3}{|c|}{$\begin{array}{l}\text { No. of CFU per ml of blood by hs post-clot } \\
\text { implantation (geometric means) }\end{array}$} & Liver" & Spleen' & Lung' \\
\hline & & & $0^{*}$ & $2 h s^{t}$ & $8 h s^{t}$ & & & \\
\hline S. aureus & $7 \times 10^{9}$ & 6 & $0.0 \times 10^{0}$ & $1.30 \times 10^{0}$ & $4.30 \times 10^{1}$ & $3.04 \times 10^{4}$ & $1.90 \times 10^{4}$ & $3.60 \times 10^{4}$ \\
\hline E. coli & $7 \times 10^{9}(06: \mathrm{H} 1: \mathrm{K} 2)$ & 3 & $0.0 \times 10^{0}$ & $0.0 \times 10^{0}$ & $2.12 \times 10^{1}$ & $8.40 \times 10^{3}$ & $1.38 \times 10^{4}$ & $2.20 \times 10^{3}$ \\
\hline E. coli & $7 \times 10^{9}(086: \mathrm{H} 8)$ & 3 & $0.0 \times 10^{0}$ & $9.48 \times 10^{0}$ & $2.83 \times 10^{1}$ & $2.30 \times 10^{3}$ & $1.32 \times 10^{3}$ & $1.09 \times 10^{3}$ \\
\hline
\end{tabular}

* To compare tissue CFU per gram at corresponding times for dogs challenged with $S$. aureus and the two $E$. coli strains, we studied two groups of dogs simultaneously. In one experiment, three dogs received $S$. aureus and three received $E$. coli $(06: \mathrm{H} 1: \mathrm{K} 2)$. In a second experiment, three dogs received $S$. aureus and three received $E$. coli $086: \mathrm{H8}$. Other details of these experiments are described in the Methods. ${ }^{\ddagger}$ At the three time points the blood culture isolates showed no significant differences $(P=N S)$. ${ }^{\S}$ The mean CFU per gram of the three organs (liver, spleen, and lung) showed significant ordered differences: $S$. aureus $>E$. coli 06:H1:K2 $>E$. coli 086:H8 $(P<0.025$, Omnibus test).

type 8) produced similar qualitative hemodynamic changes. Furthermore, this $S$. aureus was found to be more virulent than the two $E$. coli strains (per colony forming unit implanted intraperitoneally) as measured by quantitative postmortem tissue cultures (liver, lung, and spleen) and by lethality.

Other laboratory values. Results of $\mathrm{pH}$ and $\mathrm{pO}_{2}$ were normal (laboratory data not shown). Hemoglobin, sodium, potassium, bicarbonate, chloride, glucose, and calcium values were similar in all dogs infected with both viable and nonviable bacteria. None of the animals developed sufficient abnormalities in these values to explain the changes in LV function. Renal function (creatinine and blood urea nitrogen) remained normal for both control and infected dogs throughout the study.

\section{Discussion}

Septic peritonitis caused by a viable $S$. aureus produced a pattern of cardiovascular dysfunction indistinquishable from that of a viable $E$. coli. Compared to a gram-negative bacteria ( $E$. coli), this gram-positive bacteria ( $S$. aureus) (per colony forming unit implanted intraperitoneally) produced higher postmortem microorganism tissue concentrations and greater myocardial dysfunction. Viable $S$. aureus was also more lethal and more dependent on bacterial viability to produce cardiovascular changes. Despite the greater toxicity of this viable $S$. aureus, no significant endotoxemia was detected on serial blood samples using a sensitive limulus lysate assay with chromogenic substrate. The pattern of qualitative cardiovascular changes in dogs given either $S$. aureus or $E$. coli was not altered by first killing the microorganism with formalin. However, with both types of bacteria, mortality and myocardial depression decreased when formalin was used to kill the infecting microorganism.

In previous studies $(19,20)$, we implanted a viable $E$. coli into the peritoneum of dogs to study a canine model of septic shock with systolic and diastolic cardiovascular dysfunction similar to the hemodynamic profile observed in human septicemia. In the present study, a qualitatively indistinguishable pattern of cardiac abnormalities was also found using a viable and nonviable $S$. aureus and a nonviable $E$. coli. On day 2 postsurgery, after receiving adequate fluid resuscitation, animals had a decreased LVEF, dilated LV (increased EDVI and ESVI), and maintained or increased SVI and CI. These changes returned back toward normal (baseline) in 7-10 d. This pattern and time course is similar to that of human septic shock (1-3).

Clinical data from studies of human septic shock suggest that different types of microorganisms produce similar hemodynamic profiles (1-3, 7-14). The hemodynamic data obtained in this study using a canine model of septic shock are similar to data obtained from clinical studies on humans. Furthermore, the data suggest that during septic shock microorganisms with vastly different structural and molecular compositions can activate a common pathway leading to qualitatively similar severe cardiovascular dysfunction (1-3, 7-14). Presumably, the different microorganisms that cause septic shock induce the same endogenous mediators that then directly affect target tissues such as the myocardium, vascular endothelium and smooth muscle, and cells of the immune system. Even though a variety of bacteria produce a similar pattern of injury (1-3), we speculate that heterogeneity in the clinical manifestation of septicemia may depend on both host resistance factors and important but incompletely defined microorganism virulence factors, such as the ability of different microorganism to overcome host defenses, multiply, and produce toxins of variable potency.

The present study confirms that microorganisms without endotoxins can produce the same myocardial depression and hemodynamic profile produced by microorganisms with endotoxins $(19,20)$. Furthermore, although circulating endotoxin was easily detected in dogs implanted with viable or nonviable $E$. coli, endotoxin was not found in dogs infected with $S$. aureus, even though these dogs had greater myocardial depression and higher mortality. Therefore, this study does not support the idea that it is necessary for endotoxin to leak from the intestine to cause the cardiovascular dysfunction induced by $S$. aureus. Even though endotoxin has been detected in a substantial number of cases of animal and human septic shock, endotoxin is not the universal mediator of septic shock.

Compared to viable microorganisms, nonviable microorganisms (formalin-killed bacteria) produced a qualitatively similar pattern of cardiovascular dysfunction. After receiving nonviable bacteria, however, dogs were found to have less profound changes in hemodynamics and lower mortality. Furthermore, a low dose of a viable $S$. aureus (per colony forming unit implanted intraperitoneally) was more cardiotoxic than a high dose of a nonviable $S$. aureus. In contrast, a low dose of a 
viable $E$. coli (per colony forming unit implanted intraperitoneally) was less cardiotoxic than a high dose of a formalinkilled $E$. coli (Table II). Thus, viability was an important virulence factor for both types of bacteria, but compared to $E$. coli, the virulence of $S$. aureus as measured by changes in cardiac function and lethality, was more substantially reduced by formalin-killing. Although the mechanism that enables gram negative bacteria to retain cardiac and general toxicity is unknown, endotoxin, a lipopolysaccharide in the outer membrane of gram negative bacteria, is a preformed toxin resistant to both chemical and physical inactivation. These characteristics of endotoxin may account for the persistent toxicity of formalin-killed $E$. coli.

The cause of the greater loss of toxicity with this formalinkilled $S$. aureus compared to this formalin-killed $E$. coli is unknown. After examining multiple organs (liver, lung, and spleen) immediately postmortem, we found that dogs infected with viable $S$. aureus as compared to dogs infected with viable $E$. coli had higher tissue concentrations of bacteria per colony forming unit implanted intraperitoneally. The ability of $S$. aureus to replicate faster in vivo and to overcome the host defense depends on viability. Thus, loss of $S$. aureus viability would produce a greater absolute reduction in the number of bacteria that could cause cardiovascular abnormalities and lethality.

The $S$. aureus used in our experiments did not produce the exotoxin responsible for the toxic shock syndrome (TSST-1). We do not exclude the possibility, however, that some strains of $S$. aureus may produce specific exotoxins capable of inducing a septic shock syndrome identical to that traditionally associated with gram negative bacilli (30). Recently, Streptococcus pyogenes was reported to cause a shock syndrome with cardiovascular changes similar to those of gram negative septic shock (31). The occurrence of this streptococcal toxic shock syndrome, which is associated with exotoxin production, suggests that other gram positive organisms may produce a number of toxins capable of inducing a shock syndrome similar to that associated with endotoxin and gram negative sepsis. Such exotoxins would depend on bacterial viability for continued production and release, and thus this mechanism might explain the marked loss of virulence in the formalin-treated $S$. aureus group.

In this study, the strain of $S$. aureus used produced higher concentrations of bacteria in postmortem tissue (liver, lung, and spleen) and higher mortality than the $E$. coli. This $S$. aureus strain is a common human pathogen and has a virulent capsular serotype. The $E$. coli strain, (serotype $086 ; \mathrm{H} 8$ ) is an uncommon human pathogen and lacks the virulence factors commonly associated with human disease (21-23). Therefore, a second virulent $E$. coli serotype $06 ; \mathrm{H} 1 ; \mathrm{K} 2$ was also studied. This $E$. coli serotype is commonly found in human extraintestinal infections and the particular isolate was hemolytic, encapsulated, and serum-resistant, all virulence factors associated with human disease $(22,23)$. The second $E$. coli $(06 ; \mathrm{H} 1 ; \mathrm{K} 2)$, when compared to the $S$. aureus, was also found to be less virulent (per colony forming unit of viable bacteria implanted intraperitoneally) as judged by postmortem microorganism tissue concentrations and mortality. These results suggest that gram negative microorganisms with endotoxin are not necessarily more toxic than gram positive microorganisms without endotoxin. This finding underscores the importance of a microorganism's ability to produce different toxins and/or mediators that, in turn produce cardiovascular and other abnormalities. We strongly emphasize, however, that the quantitative data presented here regarding virulence per dose of implanted microorganisms pertain to the particular isolates used in this study and might not be generalizable to all gram positive and gram negative bacteria. Furthermore, infectious bacteria commonly invade humans that are immunocompromised or have an anatomic abnormality that predisposes local infection. In this present study, bacterial isolates were implanted into the normal peritoneum of healthy dogs. These host factors may have altered the bacterial kinetics of the infection.

The etiology and pathogenesis of human and animal cardiovascular dysfunction during septic shock are unknown (32). Studies in humans have demonstrated that reduced coronary blood flow is an unlikely explanation (33). Other recent studies of human septic shock have shown that a circulating myocardial depressant substance was associated qualitatively temporally with the decrease in ejection fraction (34). This substance may represent the mediator (or one of the mediators) of the myocardial depression produced by viable and nonviable $E$. coli and/or $S$. aureus microorganisms.

This present study has demonstrated that the dose, type, and viability of the injected bacteria are all critical factors affecting myocardial depression and mortality. Other factors, such as pattern of injury, time course, and cardiovascular abnormality, however, appear to be independent of bacterial type or viability, suggesting a final common pathway of injury. Furthermore, this study has shown that circulating endotoxin is neither necessary for nor specific to septic shock. These findings suggest that multiple bacterial substances are capable of triggering a common pathway resulting in similar cardiovascular injury and death.

\section{Acknowledgments}

Special thanks to Gary L. Akin, David Barrett, Mike E. Flynn, Steven Richmond, John Stewart, John K. Warrenfeltz, Nelson L. Flemming, Denise M. Ratica, and Henry Bailey, for their technical support during this study; Major James E. Hall, Major Jerome Sauber, Major James Rogers, and Captain Gordon Rahmus for veterinary care and surgical procedures; Laura L. Lewis, Walter M. Ritter, Scott A. Haram, Renee T. Cao, and Dr. Jennifer A. Burris for microbiology performed by the Clinical Pathology Service, Uniformed Services University Health Sciences; Dr. Walter Karakawa, Dr. Filipe Cabello, and Dr. Fritz Orskov for serotyping and identification procedures for the microorganisms; Dr. David W. Alling for statistical analysis; Lee Hoffman for copy editing, and Kathy Kiefer for preparing this manuscript.

Part of the funding for this research was provided by the Armed Forces Radiobiology Research Institute under task number 4441-00082.

\section{References}

1. Parker, M. M., J. H. Shelhamer, S. L. Bacharach, M. V. Green, C. Natanson, T. M. Frederick, B. A. Damske, and J. E. Parrillo. 1984 Profound but reversible myocardial depression in patients with septic shock. Ann. Intern. Med. 100:483-490.

2. Ellrodt, G. A., M. S. Riedinger, A. Kimchi, D. S. Berman, J. Maddahi, H. J. Swan, and G. H. Murata. 1985. Left ventricular performance in septic shock: reversible segmental and global abnormalities. Am. Heart J. 110:402-409.

3. Wilson, R. F., A. P. Thal, P. H. Kindling, T. Grifka, and E. 
Ackerman. 1965. Hemodynamic measurements in septic shock. Arch. Surg. 91:121-129.

4. Sanford, J. P. 1985. Epidemiology an overview of the problem. In Septic Shock: Contemporary Issues in Infectious Diseases. M. A. Sande and R. K. Root, editors. Vol. 4. Churchill Livingstone, New York, New York. 1-11.

5. Kreger, B. E., D. E. Craven, P. C. Carling, and W. R. McCabe. 1980. Gram-negative bacteremia III. Reassessment of etiology, epidemiology and ecology in 612 patients. Am. J. Med. 68:332-343.

6. Bryan, C. S., K. L. Reynolds, and E. R. Brenner. 1983. Analysis of 1,186 episodes of gram-negative bacteremia in non-university hospitals: the effects of antimicrobial therapy. Rev. Infect. Dis. 5(4):629-638.

7. Wiles, J. B., F. B. Cerra, J. H. Siegel, and J. R. Border. 1980. The systemic septic response: does the organism matter? Crit. Care Med. 8:55-60.

8. MacLean, L. D., W. G. Mulligan, A. P. McLean, and J. H. Duff. 1967. Patterns of septic shock in man: a detailed study of 56 patients. Ann. Surg. 166:543-562.

9. Winslow, E. J., H. S. Loeb, S. H. Rahimtoola, S. Kamath, and R. M. Gunnar. 1973. Hemodynamic studies and results of therapy in 50 patients with bacteremic shock. Am. J. Med. 54:421-432.

10. Siegel, J. H., M. Greenspan, and L. R. Del Guercio. 1967. Abnormal vascular tone, defective oxygen transport and myocardial failure in human septic shock. Ann. Surg. 165:504-517.

11. Clowes, G. H., Jr., G. H. Farrington, W. Zuschneid, R. Cossette, and C. Saravis. 1970. Circulating factors in the etiology of pulmonary insufficiency and right heart failure accompanying severe sepsis (peritonitis). Ann. Surg. 171:663-678.

12. Parker, M. M., J. H. Shelhamer, C. Natanson, D. W. Alling, and J. E. Parrillo. 1987. Serial cardiovascular variables in survivors and non-survivors of human septic shock in humans: heart rate as an early predictor of prognosis. Crit. Care Med. 15:923-929.

13. Weisel, R. D., L. Vito, R. C. Dennis, C. R. Valeri, and H. B. Hechtman. 1977. Myocardial depression during sepsis. Am. J. Surg. 133:512-521.

14. Krausz, M. M., A. Perel, D. Eimerl, and S. Coter. 1977. Cardiopulmonary effects of volume loading in patients in septic shock. Ann. Surg. 185:429-434.

15. Chamroen, C., and J. H. Schwab. 1984. Endotoxin-like products of gram-positive bacteria. In Handbook of Endotoxin. Chemistry of Endotoxin. Vol. 1. E. T. Reitschel, editor. Elseiver Science Publishing Co., Inc., New York. 376.

16. Fine, J. 1954. The bacterial factor in traumatic shock. I. H. Page and A. C. Corcoran, editors. Charles C. Thomas, Springfield, IL: (Publication No. 219, American Lecture Series, Monograph in American Lectures in Circulation).

17. Ravin, H. A., D. Rowley, C. Jenkins, and J. Fine. 1960. On the absorption of bacterial endotoxin from the gastro-intestinal tract of the normal and shocked animal. J. Exp. Med. 112:783-792.

18. Van Deventer, S. J. H., J. W. Ten Cate, and G. N. J. Ty Gat. 1988. Intestinal endotoxemia. Gastroenterology. 94:825-831.
19. Natanson, C., M. P. Fink, H. K. Ballantyne, T. J. MacVittie, J. J. Conklin, and J. E. Parrillo. 1986. Gram-negative bacteremia produces both severe systolic and diastolic cardiac dysfunction in a canine model that simulates human septic shock. J. Clin. Invest. 78:259-270.

20. Natanson, C., R. L. Danner, M. P. Fink, T. J. MacVittie, J. J. Conklin, and J. E. Parrillo. 1988. Cardiovascular performance with $E$. coli challenges in a canine model of human sepsis. Am. J. Physiol. 254:H558-H569.

21. Morse, S. I., and M. E. Melish. 1986. Staphlococcal. In Infectious Diseases and Medical Microbiology. A. I. Braude, editor. 2nd edition. W. B. Saunders Co., Philadelphia, PA. 237.

22. Cavalieri, S. J., G. A. Bohach, and I. S. Snyder. 1984. Escherichia coli and alpha hemolysin characteristics and probable role in pathogenicity. Microbiol. Rev. 48:326-343.

23. Young, L. S., P. Stevens, and B. Kaiser. 1982. Gram-negative pathogens in septicemic infections. Scand. J. Infect. Dis. 31:78-94.

24. Cooperstock, M. S., R. P. Tucker, and J. V. Bwublis. 1975. Possible pathogenic role of endotoxin in Reye's syndrome. Lancet. i:1272-1274.

25. Thomas, L. L., A. Sturk, H. R. Buller, J. W. TenCate, R. E. Spijker, and $\mathrm{H}$. TenCate. 1984. Comparative investigation of a quantitative chromogenic endotoxin assay and blood cultures. Am. J. Clin. Pathol. 82(2):203-206.

26. Siegel, S. 1956. Non-parametric statistics for the behavioral sciences. McGraw-Hill Book Company, Inc., New York. 229.

27. Elin, R. J., M. Foidart, B. T. Adornato, W. K. Engel, and H. R. Gralnick. 1982. Quantification of acute phase reactants after muscle biopsy. J. Lab. Clin. Med. 100:566-573.

28. Simes, R. J. 1986. An improved Bonferonni procedure for multiple tests of significance. Biometrika. 73:751-754.

29. Nelson, L. S. 1972. Tables for testing ordered alternatives in an analysis of variance. Biometrika. 64:333.

30. Rogolsky, M. 1979. Nonenteric toxins of Staphylococcus aureus. Microbiol. Rev. 43:320-360.

31. Cone, L. A., D. R. Woodard, R. M. Schlievert, and G. S. Tomory. 1987. Clinical and bacteriologic observations of a toxic shock-like syndrome due to Streptococcus pyogenes. N. Engl. J. Med. 317(3):146-149.

32. Parrillo, J. E. 1984. Septic shock: clinical manifestations, pathogenesis, hemodynamics, and management in a critical care unit. In Major Issues in Critical Care Medicine. J. E. Parrillo and S. M. Ayres, editors. Williams \& Wilkins, Baltimore, MD. 111.

33. Cunnion, R. E., G. L. Schaer, M. M. Parker, C. Natanson, and J. E. Parrillo. 1986. The coronary circulation in human septic shock. Circulation. 73:637-643.

34. Parrillo, J. E., C. Burch, J. H. Shelhamer, M. M. Parker, C. Natanson, and W. Shuette. 1985. A circulating myocardial depressant substance in humans with septic shock. Septic shock patients with a reduced ejection fraction have a circulating factor that depresses in vitro myocardial cell performance. J. Clin. Invest. 76:1539-1553. 